\title{
UJI EFEK ANTIDIARE INFUSA KOMBINASI DAUN PEPAYA (Carica papaya L.) DAN PEGAGAN (Centella asiatica (L). Urban) TERHADAP TIKUS PUTIH YANG DIINDUKSI DENGAN CASTOR OIL
}

\author{
EVALUATION OF ANTIDIARRHEAL EFFECT OF \\ COMBINATION OF PAPAYA LEAVES (Carica papaya L.) \\ AND PEGAGAN (Centella asiatica L. Urban) INFUSUM \\ IN RATS INDUCED BY CASTOR OIL
}

\author{
Kukuh Elsa Yunia Putri ${ }^{1}$, Chondrosuro Miyarso ${ }^{2}$, Husnul Khuluq ${ }^{3}$ \\ ${ }^{1}$ Sekolah Tinggi Ilmu Kesehatan Muhammadiyah Gombong \\ Jl Yos sudarso No.461 Gombong, Kebumen 54414) \\ Email: chondrosuromiyarsoapt@gmail.com,082226885341
}

Submitted :

Reviewed :

Accepted:.

\begin{abstract}
ABSTRAK
Diare merupakan pola buang air besar tidak normal yang ditandai dengan frekuensi yang meningkat dan konsistensi tinja yang menurun. Indonesia adalah negara beriklim tropis yang subur akan tanaman herbal yang dapat digunakan sebagai obat diare, di antaranya yaitu daun pepaya (Carica papaya L.) dan herba pegagan (Centella asiatica (L). Urban). Tujuan penelitian ini yaitu untuk membuktikan efek antidiare dari infusa kombinasi daun dan herba pegagan terhadap tikus putih jantan galur wistar yang telah diinduksi dengan Castor Oil (Oleum Ricini). Tikus dibagi menjadi 9 kelompok: kelompok kontrol negatif diberi Castor oil (Oleum Racini), kontrol positif diberi tanin, 5 kelompok uji infusa kombinasi daun pepaya dan herba pegagan dengan lima perbandingan setiap dosis yang diberikan secara oral, kelompok uji infusa daun pepaya tunggal, dan kelompok uji infusa herba pegagan. Hasil penelitian menunjukkan infusa daun pepaya dapat memperbaiki konsistensi feses, infusa kombinasi dengan perbandingan 1:1 dapat mengurangi frekuensi defekasi, dan infusa kombinasi dengan perbandingan 1:2 dapat mengurangi berat feses. Uji fitokimia pada kedua infusa pepaya dan herba pegagan menunjukkan positif tanin Kesimpulan penelitian ini yaitu hasil semua kelompok perlakuan menghasilkan perbedaan yang signifikan yang ditunjukkan semua kelompok perlakuan (infusa kombinasi daun pepaya dan pegagan, infusa daun pepaya, infusa herba pegagan) memiliki efek antidiare dalam menurunkan frekuensi defekasi dengan hasil terbaik pada perbandingan 1:1, konsistensi feses dengan hasil terbaik pada perbandingan 1:2, dan berat feses dengan hasil terbaik yaitu infusa daun pepaya.
\end{abstract}

Kata kunci : Infusa Daun Pepaya (Carica papaya L.), Infusa Herba Pegagan (Cantella asiatica (L).Urban), Diare, Konsistensi, Frekuensi, Bobot Feses.

\begin{abstract}
Diarrhea is an abnormal pattern of bowel movements characterized by increased frequency and decreased consistency. Indonesia is a tropical country that is fertile with herbal plants that can be used as diarrhea medicine, including papaya leaves (Carica papaya L.) and Herba pegagan (Centella asiatica (L). Urban). The aim of this study was to prove the antidiarrheal effect of a combination infusion of pepaya leaf and herb of pegagan on male white rats of wistar strain that had been induced with Castor oil (Oleum Racini). Rats were divided into 9 groups: the negative control group was given Castor oil (Oleum Racini), the
\end{abstract}


positive control was given tannins, 5 groups were given a combination of pepaya leaf and herb of pegagan infusion test with five comparisons of each dose given orally, single pepaya leaf infusion test group, and herb of pegagan infusion test group. The results showed that pepaya leaf infusion could improve stool consistency, combination of infusion with a ratio of 1:1 could reduce the frequency of defecation, and a combination of infusion with a concentration ratio of 1:2 could reduce stool weight. Phytochemical tests on both infusions showed positive tannins. The conclusion show that all combinations of infusion have antidiarrheal effect with decreased frequency of defecation, feces consistency, and feces weight with good result at ratio of 1:1,1:1, and papaya leaf infusion.

Keywords: Infusion of Papaya Leaf (Carica papaya L.), Infusion of Pegagan (Cantella asiatica (L). Urban), Diarrhea, Consistency, Frequency, Weight of Stool.

\author{
Penulis Korespondensi : \\ Kukuh Elsa Yunia Putri \\ Sekolah Tinggi Ilmu Kesehatan Muhammadiyah Gombong \\ Jl Yos sudarso No.461 Gombong, Kebumen 54414 \\ Email : chondrosuromiyarsoapt@gmail.com
}

\title{
PENDAHULUAN
}

Saat ini diare menjadi penyakit masyarakat yang menjadi kontributor utama nomor tiga angka kesakitan dan kematian pada anak di seluruh penjuru dunia termasuk Indonesia. 1,3 miliar dan 3,2 juta kasus meninggal dunia pada balita penyebabnya adalah diare. (Priatna, 2016). Diare merupakan pola buang air besar tidak normal yang ditandai dengan frekuensi yang meningkat dan konsistensi tinja yang menurun. Muntah, kehilangan banyak air dengan garam-garamnya terutama natrium dan kalium yang selanjutnya menyebabkan dehidrasi, kekurangan kalium (hypokalemia) serta adakalanya asidosis dan yang tidak jarang adalah syok dan kematian juga menjadi akibat dari diare hebat (Tjay \& Kirana, 2007).

Menurut Riskesdas (2018), jumlah kasus diare yang ditangani pada tahun 2016 sebanyak 3.176.079 kasus serta terjadi penambahan kasus di tahun 2017 menjadi 4.274.790 kasus atau apabila diprosentasekan 60,4\% dari perkiraan diare di sarana kesehatan. Dinas Kesehatan Provinsi Jawa Tengah (2017) menyatakan kasus diare yang ditangani di Jawa Tengah pada tahun 2017 sebesar 55,8 persen. Data ini menunjukkan terjadinya penurunan bila dibandingkan dengan angka kejadian di tahun 2016 yaitu sebanyak 68,9 persen. Sedangkan data Dinas Kesehatan Kab. Kebumen (2017) mendapatkan hasil cakupan penemuan penderita diare di kabupaten Kebumen yaitu 105,8\%.

Pada umumnya, pengobatan secara farmakologi untuk diare memberikan solusi sebagai penahan peristaltik, spasme usus, iritasi dan penawar racun. Obat konvensional yang digunakan untuk diare antaralain seperti loperamid dan bismuth subsalisilat (Tjay \& Kirana, 2007). World Health Organization (WHO) mendukung upaya dalam meningkatkan keamanan dan khasiat dari obat tradisional. Selain itu juga menganjurkan penggunaan obat tradisional dalam memelihara kesehatan masyarakat, mencegah dan mengobati penyakit.

Word Health Orgaization (WHO) ini juga mendukung studi untuk pengobatan dan pencegahan dari penyakit diare dengan melibatkan praktek pengobatan tradisional. Dengan adanya isu back to nature juga ikut serta menjadikan penggunaan tanaman obat berkembang sangat pesat dan kembali diminati sehingga obat tradisional menjadi salah satu alternatif pengobatan yang diakui dunia. Dengan adanya fenomena ini maka obat tradisional sangat perlu dimanfaatkan dengan sebaik-baiknya (Pusmarani \& Saranani, 2018). 
Penggunaan tanaman herbal untuk diare masih sangat terbatas. Sejauh ini hanya daun jambi biji (Psidium guajava L.). Sehingga perlu dikembangkan dengan menggunakan bahan alam lain yang mempunyai potensi sama sebagai antidiare.

Indonesia adalah negara beriklim tropis yang subur akan tanaman herbal yang dapat digunakan sebagai obat diare. Di antaranya yaitu daun pepaya (Carica papaya L.) dan herba pegagan (Centella asiatica (L). Urban). Dalam penelitian yang dilakukan oleh A'yun \& Laily (2015) menyebutkan bahwa daun pepaya (Carica papaya L.) mengandung senyawa alkaloid, karpain, violaksantin, papain, saponin, flavonoid dan tanin. Tanaman lainnya yaitu pegagan (Centella asiatica (L). Urban) yang juga mengadung senyawa alkaloid, saponin, steroid dan tanin (Bermawie et al., 2015)

Untuk mengembangkan penemuan obat-obat baru, maka penulis tertarik untuk meneliti daun pepaya (Carica papaya L.) yang dikombinasi dengan herba pegagan (Cantella asiatica (L). Urban) yang dibuat infusa dan diuji efek antidiarenya menggunakan minyak jarak sebagai larutan penyebab diare pada tikus putih. Penelitian ini bertujuan untuk mengetahui uji efek antidiare infusa kombinasi daun pepaya (Carica papaya L.) dan pegagan (Centella asiatica (L). Urban) dengan menggunakan metode Costor Oil - Induced Diarrhea.

\section{METODE PENELITIAN}

\section{Alat dan Bahan}

Alat yang digunakan pada penelitian ini adalah corong (Iwaki), termometer (Borosil), tabung reaksi (Pyrex), jarum sonde (Terumo), timbangan hewan (Ohaus), dan timbangan analitik (Ohaus).

Bahan yang digunakan pada penelitian ini adalah aquadest (Smartlab), castor oil (Smartlab), tanin (Smartlab), $\mathrm{FeCl}_{3} 5 \%$ ( $s=$ Smartlab), dan $\mathrm{H}_{2} \mathrm{SO}_{4}$ (Smartlab). Sedangkan sampel berupa daun pepaya (Carica papaya L..) dan pegagan (Centella asiatica (L). Urban) diperoleh dari Desa Selanegara, kecamatan Sumpiuh, Kabupaten Banyumas. Hewan uji yang digunakan yaitu tikus putih jantan galur wistar, umur 2-3 bulan, dan berat badan 100-800 gram.

\section{Jalannya Penelitian}

2. Pembuatan infusa

a. Infusa Daun Pepaya (Carica papaya L.)

Daun pepaya (Carica papaya L.) segar sebanyak 87,5 gram dibersihkan dan dicuci menggunakan air mengalir diikuti dengan aquadest untuk menghilangkan partikel asing. Kemudian daun pepaya (Carica papaya L.) masukkan ke dalam panci dengan air sebanyak $300 \mathrm{ml}$. Panaskan diatas penagas air selama 15 menit terhitung dari suhu $90^{\circ} \mathrm{C}$ sambil sesekali diaduk. Selanjutnya, disaring selagi panas menggunakan kain flanel, panaskan di atas magnetic stirrer hingga volume infusa sebanyak $100 \mathrm{ml}$.

b. Infusa Pegagan (Centella asiatica (L). Urban)

Pegagan (Centella asiatica (L). Urban) segar sebanyak 87,5 gram dibersihkan dan dicuci menggunakan air mengalir diikuti dengan aquades untuk menghilangkan partikel asing. Kemudian pegagan (Centella asiatica (L). Urban) masukkan ke dalam panci dengan air sebanyak 300ml. Panaskan diatas penagas air selama 15 menit terhitung dari suhu $90^{\circ} \mathrm{C}$ sambil sesekali diaduk. Selanjutnya, disaring selagi panas menggunakan kain flanel, Pembuatan infusa kombinasi daun pepaya (Carica papaya L) dan pegagan (Centella asiatica (L). Urban) panaskan di atas magnetic stirrer hingga volume infusa sebanyak $100 \mathrm{ml}$.

3. Uji Kualitatif Tanin

Siapkan $5 \mathrm{ml}$ infusa daun pepaya (Carica papaya L.) di tempatkan ke dalam tabung dan $5 \mathrm{ml}$ pegagan (Centella asiatica (L). Urban) juga di tempatkan ke dalam tabung terpisah. Masing-masing infusa ditambahkan dengan $\mathrm{FeCl}_{3} 5 \%+\mathrm{H}_{2} \mathrm{SO}_{4}$ masing-masing 
3 tetes. Reaksi positif untuk tanin ditunjukkan dengan perubahan warna cairan menjadi warna kuning-kehijauan.

4. Persiapan Hewan Uji

Hewan uji berupa tikus putih dengan berat badan 100-180 gram, umur 2-3 bulan, dan sehat diadaptasi selama 1 minggu dalam kandang di Laboratorium Farmakologi Farmasi Stikes Muhammadiyah Gombong agar dapat beradaptasi dengan lingkungan baru. Hewan uji diberi makan dan minum secara rutin serta dilakukan pengamatan rutin. Sebelum perlakuan, hewan uji dipuasakan selama lebih kurang 18 jam, namun tetap diberikan air minum.

5. Perlakuan Terhadap Hewan Uji

Hewan uji yang digunakan sebanyak 36 ekor yang dibagi menjadi 9 kelompok perlakuan dan setiap kelompok terdiri atas 4 ekor hewan uji. Sebelum perlakuan, hewan uji ditimbang terlebih dahulu. Kemudian, semua hewan uji dikelompokkan secara acak sebagai berikut :

1) Kelompok I (kontrol negatif) : disonde dengan Castor oil (Oleum ricini) $2 \mathrm{ml}$ dan aquades $2 \mathrm{ml}$.

2) Kelompok II (kontrol positif) : disonde dengan Castor oil (Oleum ricini) $2 \mathrm{ml}$ kemudian diberikan larutan tanin murni 0,5 gram $(65 \mathrm{mg} / \mathrm{kg} \mathrm{BB})$.

3) Kelompok III (perlakuan) : disonde dengan Castor oil (Oleum ricini) $2 \mathrm{ml}$ kemudian diberikan infusa kombinasi daun pepaya (Carica papaya L.) dan herba pegagan (Centella asiatica (L). Urban) dengan kadar $87,5 \%$ b/v (1:1)

4) Kelompok IV (perlakuan) : disonde dengan Castor oil (Oleum ricini) $2 \mathrm{ml}$ kemudian diberikan infusa kombinasi daun papaya (Carica papaya L.) dan herba pegagan (Centella asiatica (L). Urban) dengan kadar $87,5 \%$ b/v (2:1)

5) Kelompok V (perlakuan) : disonde dengan Castor oil (Oleum ricini) $2 \mathrm{ml} \mathrm{kemudian}$ diberikan infusa kombinasi daun pepaya (Carica papaya L.) dan pegagan (Centella asiatica (L). Urban) dengan kadar 87,5\% b/v (3:1)

6) Kelompok VI (perlakuan) : disonde dengan Castor oil (Oleum ricini) $2 \mathrm{ml}$ kemudian diberikan infusa kombinasi daun pepaya (Carica papaya L.) dan pegagan (Centella asiatica (L). Urban) dengan kadar 87,5\% b/v (1:3)

7) Kelompok VII (perlakuan) : disonde dengan Castor oil (Oleum ricini) $2 \mathrm{ml}$ kemudian diberikan infusa kombinasi daun pepaya (Carica papaya L.) dan pegagan (Centella asiatica (L). Urban) dengan kadar 87,5 \% b/v (1:2)

8) Kelompok VIII (perlakuan) : disonde dengan Castor oil (Oleum ricini) $2 \mathrm{ml}$ kemudian diberikan infusa daun pepaya (Carica papaya L.) dengan kadar 87,5\% $\mathrm{b} / \mathrm{v}$

9) Kelompok IX (perlakuan) : disonde dengan Castor oil (Oleum ricini) $2 \mathrm{ml}$ kemudian diberikan infusa pegagan dengan kadar $87,5 \% \mathrm{~b} / \mathrm{v}$

Hewan uji di masukkan ke dalam bejana individual untuk menunggu feses yang dihasilkan selama 5 jam, kemudian diamati konsistensi feses, frekuensi defekasi dan berat feses yang dihasilkan.

\section{Analisis Data}

Metode analisis data yang digunakan adalah SPSS dengan metode uji ANOVA post hoc LSD untuk melihat rincian perkonsentrasi infusa atau perperlakuan terhadap hewan uji. 
HASIL DAN PEMBAHASAN

Tabel I. Aktivitas Diare Tikus

\begin{tabular}{|c|c|c|c|c|c|}
\hline Kelompok & Tikus & $\begin{array}{c}\text { Total } \\
\text { Konsistensi }\end{array}$ & $\begin{array}{c}\text { Rata-rata } \\
\text { Konsistensi }\end{array}$ & $\begin{array}{c}\text { Total } \\
\text { Frekuensi }\end{array}$ & $\begin{array}{c}\text { Total Berat } \\
\text { Feses }\end{array}$ \\
\hline \multirow[t]{4}{*}{$\mathrm{I}(+)$} & 1 & 7 & 1.4 & 6 & 2 \\
\hline & 2 & 7 & 1.75 & 7 & 1,19 \\
\hline & 3 & 8 & 1.6 & 5 & 1,49 \\
\hline & 4 & 8 & 1.6 & 1 & 0,97 \\
\hline \multirow{4}{*}{ II (-) } & 1 & 14 & 1.75 & 36 & 6,58 \\
\hline & 2 & 15 & 2.5 & 26 & 5,06 \\
\hline & 3 & 12 & 2.4 & 15 & 6,15 \\
\hline & 4 & 13 & 2.17 & 20 & 7,02 \\
\hline \multirow[t]{4}{*}{ III ( $1: 1)$} & 1 & 8 & 2.00 & 5 & 2,15 \\
\hline & 2 & 9 & 1.8 & 3 & 1,53 \\
\hline & 3 & 8 & 2.00 & 4 & 1,47 \\
\hline & 4 & 7 & 1.75 & 5 & 1,36 \\
\hline \multirow[t]{4}{*}{ IV (1:2) } & 1 & 19 & 2.11 & 26 & 3,61 \\
\hline & 2 & 9 & 1.8 & 18 & 3,73 \\
\hline & 3 & 8 & 2.00 & 15 & 2,98 \\
\hline & 4 & 10 & 1.43 & 23 & 2,92 \\
\hline \multirow[t]{4}{*}{$\mathrm{V}(2: 1)$} & 1 & 12 & 1.71 & 13 & 2,93 \\
\hline & 2 & 12 & 1.71 & 12 & 2,14 \\
\hline & 3 & 8 & 1.6 & 10 & 2,36 \\
\hline & 4 & 19 & 2.38 & 19 & 2,17 \\
\hline \multirow[t]{4}{*}{ VI (1:3) } & 1 & 10 & 2.00 & 17 & 2,23 \\
\hline & 2 & 13 & 1.44 & 27 & 2,92 \\
\hline & 3 & 14 & 2.33 & 13 & 2,23 \\
\hline & 4 & 6 & 2.00 & 9 & 2,96 \\
\hline \multirow[t]{4}{*}{ VII (3:1) } & 1 & 15 & 2.5 & 14 & 1,5 \\
\hline & 2 & 10 & 1.67 & 14 & 2,51 \\
\hline & 3 & 9 & 1.12 & 12 & 2,69 \\
\hline & 4 & 6 & 2.00 & 9 & 1,77 \\
\hline \multirow[t]{3}{*}{$\begin{array}{l}\text { VIII (Infusa } \\
\text { Pepaya) }\end{array}$} & 1 & 12 & 1.5 & 16 & 2,62 \\
\hline & 2 & 13 & 1.86 & 12 & 1,21 \\
\hline & 3 & 14 & 1.56 & 23 & 1,81 \\
\hline
\end{tabular}




\begin{tabular}{cccccc} 
& 4 & 8 & 1.33 & 8 & 1,43 \\
IX (Infusa & 1 & 13 & 2.17 & 18 & 3,85 \\
Pegagan) & 1 & 11 & 1.83 & 13 & 2,72 \\
& 2 & 10 & 1.67 & 11 & 2,02 \\
& 3 & 15 & 2.14 & 13 & 1,64 \\
\hline
\end{tabular}

Keterangan :

I. Kelompok tikus yang diberikan Castor oil $2 \mathrm{ml}$ dan kemudian dibeikan larutan tanin sebagai pembanding

II. Kelompok tikus yang diberikan Castor oil $2 \mathrm{ml}$ dan kemudian diberikan aquades sebagai kontrol

III. Kelompok tikus yang diberikan Castor oil $2 \mathrm{ml}$ dan kemudian diberikan infusa kombinasi daun pepaya dan herba pegagan (1:1)

IV. Kelompok tikus yang diberikan Castor oil $2 \mathrm{ml}$ dan kemudian diberikan infusa kombinasi daun pepaya dan herba pegagan (2:1)

V. Kelompok tikus yang diberikan Castor oil $2 \mathrm{ml}$ dan kemudian diberikan infusa kombinasi daun pepaya dan herba pegagan (3:1)

VI. Kelompok tikus yang diberikan Castor oil $2 \mathrm{ml}$ dan kemudian diberikan infusa kombinasi daun pepaya dan herba pegagan (1:3)

VII. Kelompok tikus yang diberikan Castor oil $2 \mathrm{ml}$ dan kemudian diberikan infusa kombinasi daun pepaya dan herba pegagan (1:2)

VIII. Kelompok tikus yang diberikan Castor oil $2 \mathrm{ml}$ dan kemudian diberikan infusa daun pepaya

IX. Kelompok tikus yang diberikan Castor oil $2 \mathrm{ml}$ dan kemudian diberikan infusa herba pegagan

Tabel II. Perbedaan Rerata dan Nilai p-value Berdasarkan Uji ANOVA Post Hoc LSD

\begin{tabular}{|c|c|c|c|c|c|c|}
\hline Kelompok & $\begin{array}{c}p \text {-value } \\
\text { Konsistensi }\end{array}$ & $\begin{array}{l}\text { Perbedaan } \\
\text { rerata }\end{array}$ & $\begin{array}{l}p \text {-value } \\
\text { Frekuensi }\end{array}$ & $\begin{array}{l}\text { Perbedaan } \\
\text { Rerata }\end{array}$ & $\begin{array}{c}p \text {-value } \\
\text { Berat Feses }\end{array}$ & $\begin{array}{c}\text { Perbedaan } \\
\text { Rerata }\end{array}$ \\
\hline$(-)$ Vs $(+)$ & 0,012 & 0,617 & 0,000 & 19,50 & 0,000 & 4,790 \\
\hline $\begin{array}{c}(-) \text { vs }(1: 1) \\
\text { III }\end{array}$ & 1,117 & 0,317 & 0,000 & 20,00 & 0,000 & 4,575 \\
\hline $\begin{array}{c}(-) \text { vs }(2: 1) \\
\text { IV }\end{array}$ & 0,133 & 0,355 & 0,007 & 10,75 & 0,000 & 3,802 \\
\hline $\begin{array}{c}(-) \text { vs }(3: 1) \\
\text { V }\end{array}$ & 0,107 & 0,382 & 0,003 & 12,00 & 0,000 & 4,085 \\
\hline $\begin{array}{c}(-) \text { vs }(1: 3) \\
\text { VI }\end{array}$ & 0,262 & 0,262 & 0,045 & 7,75 & 0,000 & 3,617 \\
\hline $\begin{array}{c}(-) \text { vs }(1: 2) \\
\text { VII }\end{array}$ & 0,118 & 0,370 & 0,317 & 3,75 & 0,000 & 2,892 \\
\hline $\begin{array}{l}\text { (-) vs (Infusa } \\
\text { Pepaya) }\end{array}$ & 0,009 & 0,642 & 0,016 & 9,50 & 0,000 & 4,437 \\
\hline $\begin{array}{c}\text { VIII } \\
\text { (-) vs (Infusa } \\
\text { Pegagan) } \\
\text { IX }\end{array}$ & 0,280 & 0,252 & 0,008 & 10,50 & 0,000 & 3,645 \\
\hline
\end{tabular}


Hasil uji fitokimia secara kualitatif pada infusa daun pepaya (Carica papaya L.) dan herba pegagan (Centella asiatica (L). Urban) dengan menggunakan $\mathrm{FeCl}_{3}$ dan $\mathrm{H}_{2} \mathrm{SO}_{4}$ menunjukkan adanya tanin.

Efek antidiare dari infusa daun pepaya (Carica papaya L.) dan herba pegagan (Centella asiatica (L). Urban) diuji menggunakan 9 kelompok tikus putih jantan galur wistar, dimana masing-masing kelompok terdiri dari 4 ekor tikus. Kelompok II sebagai kelompok kontrol negatif diberi aquades. Kelompok I sebagai kelompok kontrol positif diberikan lrutan tanin murni. Kelompok perlakuan III, IV, V, VI, VII diberi kombinasi infusa daun pepaya (Carica papaya L.) dan herba pegagan (Centella asiatica (L). Urban) (1:1, 2:1, $3: 1,1: 3,1: 2)$, dan kelompok perlakuan VIII dan IX, masing-masing diberi infusa daun pepaya tunggal dan herba pegagan tunggal.

Semua parameter data normal dan homogen $(p>0,05)$. Untuk mengetahui adanya perbedaan yang bermakna antara kelompok perlakuan, maka dilakukan uji lanjutan yaitu uji Post Hoc LSD. Dari hasil analisis uji, diperoleh perbedaan yang signifikan pada hampir semua parameter, kecuali kelompok III, IV, V, VI, VII,dan IX pada parameter konsistensi feses. (lihat tabel II).

Pada penelitian ini terdapat perbedaan yang signifikan antara kelompok I dan II, dimana kelompok kontrol negatif yang diberikan Castor oil dan aquades, dan kelmpok kontrol positif yang diberikan Castor oil kemudian diberikan larutan tanin. Kelompok kontrol positif memiliki perbedaan yang signifikan dengan kelompok kontrol negatif pada konsistesi feses, frekuensi defekasi, dan berat feses. Hasil ini sejalan dengan penelitian oleh Khuluq \& Marlina (2021) dengan menggunakan 9 uji perlakuan, dimana kontrol positif yang diberikan tanin sebelum pemberian Castor oil memiliki perbedaan yang signifikan pada kelompok kontrol negatif yang diberikan 1\% CMC dan Castor oil pada berat feses, frekuensi defekasi, dan konsistensi feses.

Hal ini sesuai dengan teori yang menyatakan bahwa diare terjadi karena ketidakseimbangan antara absorbsi dan ekskresi cairan dan elektrolit pada saluran pencernaan yang bisa menyebabkan hilangya air dan elektrolit bersama dengan feses. Secara umum ada berbagai macam mekanisme yang dapat menyebabkan diare, yaitu gangguan keseimbangan elektrolit, hipermotilitas, peningkatan osmolaritas dan peningkatan sekresi. Penggunaan Castor oil sebagai penginduksi diare sangat logis, karena pemecahan asam rinoleat dari Castor oil dapat menyebabkan iritasi dan inflamasi pada mukosa intestinal. Sehingga menyebabkan stimulus rilis prostaglandin sehingga mengakibatkan peningkatan sekresi serta motilitas intestinal (Fajrin, 2012).

Tanin yang terdapat pada infusa daun pepaya (Carica papaya L.) dan herba pegagan (Centella asiatica (L). Urban) dapat menghambat motilitas dan sekresi yang disebabkan oleh Castor oil. Hal ini terjadi karena tanin sebagai pengkhelat mempunyai efek spasmolitik yang dapat mengkerutkan usus sehingga gerak peristaltik usus berkurang (Fratiwi, 2015).

Hasil semua kelompok perlakuan menghasilkan perbedan yang signifikan yang ditunjukkan bahwa semua kelompok perlakuan (infusa kombinasi daun pepaya dan herba pegagan, infusa daun pepaya, dan infusa herba pegagan) memiliki efek antidiare dalam menurunkan konsistensi feses, frekuensi defekasi, dan berat feses). Oleh karenanya tanin sebagai senyawa aktif mungkin memiliki efek pada aktivitas dari antidiare (Khuluq \& Marlina, 2021). Hasil terbaik dalam mengurangi frekuensi defekasi adalah kombinasi infusa dengan perbandingan 1:1. Hasil terbaik dalam mengurangi berat feses adalah kombinasi infusa dengan perbandingan 1:2, dan hasil terbaik dalam memperbaiki konsistensi feses adalah infusa pepaya. 


\section{KESIMPULAN}

Perlakuan dengan kombinasi infusa daun pepaya dan herba pegagan memiliki efek antidiare. Hasil terbaik dalam mengurangi frekuensi defekasi adalah kombinasi infusa dengan perbandingan 1:1. Hasil terbaik dalam mengurangi berat feses adalah kombinasi infusa dengan perbandingan 1:2, dan hasil terbaik dalam memperbaiki konsistensi feses adalah infusa pepaya.

\section{DAFTAR PUSTAKA}

A'yun, Q., \& Laily, A. N. (2015). Analisis Fitokimia Daun Pepaya (Carica papaya L.) Di Balai Penelitian Tanaman Aneka Kacang dan Umbi, Kendalpayak, Malang. Pendidikan Biologi, Pendidikan Geografi, Pendidikan Sains, PKLH - FKIP UNS, 134-137.

Bermawie, N., Purwiyanti, S., Penelitian, B., Obat, T., Penelitian, P., Cicurug, K. P., \& Germplasm, L. U. (2015). KERAGAAN SIFAT MORFOLOGI, HASIL DAN MUTU PLASMA NUTFAH PEGAGAN (Centella asiatica (L.) Urban.). Buletin Penelitian Tanaman Rempah Dan Obat, 19(1), 1-17..

Dinas Kesehatan Kab. Kebumen. (2017). PROFIL KESEHATAN KABUPATEN KEBUMEN 2017. Kebumen: Dinas Kesehatan Kabupaten Kebumen.

Dinas Kesehatan Provinsi Jawa Tengah. (2017). Profil Kesehatan Provinsi Jawa Tengah Tahun 2017. Semarang: Dinas Kesehatan Provinsi Jawa Tengah.

Fajrin, F. A. (2012). AKTIVITAS ANTIDIARE EKSTRAK ETANOL DAUN SELEDRI (Apium graveolens L.) PADA MENCIT JANTAN. Jurnal Ilmiah Farmasi, 9(1), 1-8.

Fratiwi, Y. (2015). The Potential Of Guava Leaf (Psidium guajava L.) For Diarrhea. Majority, 4(1), 113-118.

Khuluq, H., \& Marlina, E. (2021). Evaluation of Antidiarrheal Effect of Combination of Salam Leaves ( Syzygiumpolyanthum ) and Jackfruit Leaves ( Artocarpus heterophyllus Lam.) Infusum in Rats induced by Castor oil. Pharmacy Education.

Priatna, H. E. M. (2016). PENGARUH REBUSAN AKAR BAYAM DURI (Amaranthus spinosus L.) TERHADAP DIARE PADA MENCIT JANTAN GALUR SWISS WEBSTER, 16, 57-60.

Pusmarani, J., \& Saranani, S. (2018). Aktivitas Antidiare Buah Okra (Abelmoschus esculentus L.) Pada Mencit Yang Diinduksi Oleum Ricini. Jurnal Mandala Pharmacon Indonesia, 4(02), 102-108.

Riskesdas. (2018). Hasil Utama Riset Kesehatan Dasar 2018. Kementrian Kesehatan Republik Indonesia. Jakarta.

Tjay, T. H., \& Kirana. (2007). Obat-Obat Penting, Khasiat, Penggunaan dan Efek-Efek Sampingnya (5th ed.). Departemen kesehatan Republik Indonesia. 